\title{
The Apache Longbow-Hellfire Missile Test at Yuma Proving Ground: Ecological Risk Assessment for Missile Firing
}

\author{
Daniel S. Jones, ${ }^{1,2}$ Rebecca A. Efroymson, ${ }^{1}$ William W. Hargrove, ${ }^{1}$ \\ Glenn W. Suter II, ${ }^{3}$ and Larry L. Pater ${ }^{4}$ \\ ${ }^{1}$ Environmental Sciences Division, Oak Ridge National Laboratory (ORNL), Oak \\ Ridge, TN, USA; ${ }^{2}$ Currently at Arcadis, Knoxville, TN, USA $;{ }^{3}$ U.S. Environmental \\ Protection Agency, National Center for Environmental Assessment, Cincinnati, \\ OH, USA; ${ }^{4}$ U.S. Army Engineer Research and Development Center, Construction \\ Engineering Research Laboratory, Champaign, IL, USA
}

\begin{abstract}
A multiple stressor risk assessment was conducted at Yuma Proving Ground, Arizona, as a demonstration of the Military Ecological Risk Assessment Framework. The focus was a testing program at Cibola Range, which involved an Apache Longbow helicopter firing Hellfire missiles at moving targets, that is, M60-A1 tanks. This article describes the ecological risk assessment for the missile launch and detonation. The primary stressor associated with this activity was sound. Other minor stressors included the detonation impact, shrapnel, and fire. Exposure to desert mule deer (Odocoileus hemionus crooki) was quantified using the Army sound contour program BNOISE2, as well as distances from the explosion to deer. Few effects data were available from related studies. Exposure-response models for the characterization of effects consisted of human "disturbance" and hearing damage thresholds in units of C-weighted decibels (sound exposure level) and a distance-based No-ObservedAdverse-Effects Level for moose and cannonfire. The risk characterization used a weight-of-evidence approach and concluded that risk to mule deer behavior from the missile firing was likely for a negligible number of deer, but that no risk to mule deer abundance and reproduction is expected.
\end{abstract}

Received 9 February 2007; revised manuscript accepted 1 September 2007.

This article has been authored by a contractor of the U.S. Government under contract DEAC05-00OR22725. Accordingly, the U.S. Government retains a nonexclusive, royalty-free license to publish or reproduce the published form of this contribution, or allow others to do so, for U.S. Government purposes.

William W. Hargrove is currently affiliated with the USDA Forest Service, Eastern Forest Environmental Threat Assessment Center, Asheville, NC, USA.

Address correspondence to Rebecca A. Efroymson, Environmental Sciences Division, Oak Ridge National Laboratory (ORNL), Oak Ridge, TN 37831-6036, USA. E-mail: efroymsonra@ornl.gov 
Key Words: ecological risk assessment, impulsive sound, blast noise, missile, mule deer, Sonoran desert, military.

\section{INTRODUCTION}

Ecological impacts of military training and testing programs involving the firing of large caliber munitions such as missiles are investigated in gray literature such as U.S. National Environmental Policy Act environmental impact assessments. Moreover, impacts of ordnance on wildlife have been studied in the context of opportunistic research on military installations. Such research has involved effects of artillery munitions or smaller weapons in training activities on white-tailed deer (Odocoileus virginianus) at Fort Sill, OK, USA (Dinkines et al. 1992), wolf (Canis lupus) movements at Camp Ripley National Guard Training Site in Little Falls, MN, USA (Merrill and Erickson 2003), black bear (Ursus americanus) movements at the U.S. Marine Corps Base Camp Lejeune, NC, USA, Sonoran pronghorn (Antilocapra americana sonoriensis) at Barry M. Goldwater Range, AZ, USA, red-cockaded woodpecker (Picoides borealis) at Fort Benning, GA, USA (Delaney et al. 2002) and Fort Stewart, GA, USA (Doresky et al. 2001), and raptors in military training areas of the Snake River Birds of Prey National Conservation Area, ID, USA (Schueck et al. 2001, Lehman et al. 1999). Efroymson et al. (2008, in press) reviewed wildlife habitat disturbances at military ranges where explosives are in use.

Until now, impacts of missiles and other military activities involving physical stressors have not been investigated through the use of an ecological risk assessment framework. The U.S. Environmental Protection Agency's (USEPA's) Guidelines for Ecological Risk Assessment (USEPA 1998) are written to apply broadly to any chemical, physical, or biological stressor and should be applicable to missile launch and detonation. The Military Ecological Risk Assessment Framework (MERAF) was developed as an elaboration of the USEPA guidelines for multiple military activities (Suter et al. 2002).

This article aims to assess the risks associated with the missile firing activity of the Apache Longbow-Hellfire missile test at Yuma Proving Ground (YPG) to desert mule deer (Odocoileus hemionus crooki). Moreover, data gaps that would reduce uncertainty in risk assessments for these stressors are discussed. This is one of a series of articles describing an ecological risk assessment for a military program at YPG that was conducted to demonstrate MERAF. The Apache Longbow-Hellfire missile test and problem formulation for the risk assessment are described in Efroymson et al. (2008a) in this issue of Human and Ecological Risk Assessment. Ecological risk assessments for other military activities associated with the test at YPG are described in Efroymson et al. (2008b, helicopter overflights) and Peterson et al. (2008, tracked vehicle movement).

\section{PROBLEM FORMULATION}

\section{Potential Stressors, Modes of Action, and Conceptual Models}

Candidate stressors to desert mule deer that are associated with missile firing are presented in Table 1. An activity-specific risk assessment framework is not available 


\section{S. Jones et al.}

Table 1. Stressors and modes of action associated with missile firing.

\begin{tabular}{|c|c|}
\hline Stressor & Potential mode of action \\
\hline Sound & $\begin{array}{l}\text { Behavioral response of } \\
\text { wildlife, auditory damage } \\
\text { to wildlife, interference } \\
\text { with foraging or predation, } \\
\text { interference with mating }\end{array}$ \\
\hline Impact detonation & $\begin{array}{l}\text { Injury to wildlife and } \\
\text { vegetation, modification of } \\
\text { local hydrology }\end{array}$ \\
\hline Shrapnel & $\begin{array}{l}\text { Death or injury of wildlife and } \\
\text { vegetation }\end{array}$ \\
\hline Fire & $\begin{array}{l}\text { Death or injury of vegetation } \\
\text { and behavioral response of } \\
\text { wildlife }\end{array}$ \\
\hline Chemical residue & $\begin{array}{l}\text { Contamination of soil, water, } \\
\text { and food items; toxicity to } \\
\text { wildlife and vegetation }\end{array}$ \\
\hline Unexploded ordnance & $\begin{array}{l}\text { Death or injury of wildlife and } \\
\text { vegetation }\end{array}$ \\
\hline
\end{tabular}

for this activity, as it was for the companion risk assessment of the helicopter overflight (Efroymson et al. 2008b, in press). All stressors that could be significant in this assessment for YPG are included. Some were determined to be insignificant (e.g., sound of missile launch) following the problem formulation and were not carried through the entire risk assessment process. Unexploded ordnance (UXO) was included in Table 1 for the sake of completeness but was deemed to be outside the scope of this demonstration of MERAF. UXO would probably be more appropriately addressed in a separate framework focusing on the unique aspects of that stressor. Also, UXO is not a significant problem for a testing activity of this size and frequency; tracking and recovery or destruction of individual warheads is feasible at this scale. The desert mule deer assessment endpoint is described in detail in Efroymson et al. (2008a, in press). The conceptual model for missile firing is depicted in Figure 1.

\section{Selection of Activity-Specific Measures of Exposure}

\section{Intensity measures}

Sound. The two principal measures of exposure to sound that provide a description of a Hellfire launch and detonation are the sound exposure level (SEL) and peak sound level (Lmax). The SEL takes into account both the maximum noise level of an event and its duration; it represents the sound if all of the acoustic energy of an event were compressed into one second. SEL is generally considered to be meaningful for evaluating wildlife responses to noise (Krausman et al. 2004). Furthermore, decibels at various frequencies are adjusted (weighted) to represent the way the average human ear responds to various frequencies of sound. C-weighting is the human auditory weighting generally used for blast noise. C-weighting differs 


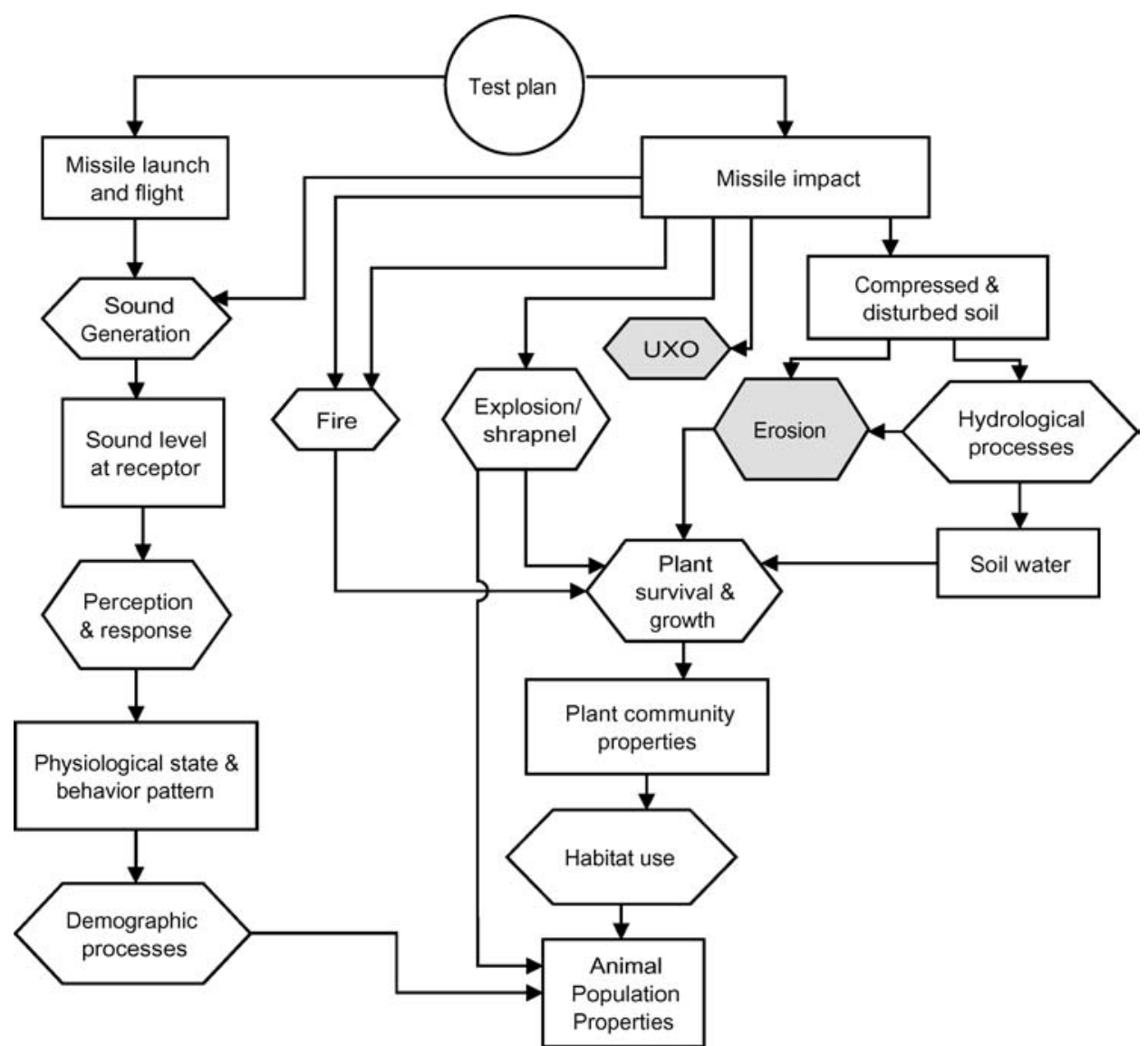

Figure 1. Conceptual model for Hellfire missile firing component of Apache Longbow-Hellfire missile test at Yuma Proving Ground. Rectangles are states, hexagons are processes, and the circle indicates the test plan. Stressors and/or portions of the activity that were not considered in this assessment appear in gray.

from A-weighting in that it gives almost equal weighting to all sound frequencies (Telesco and van Manen 2006).

Frequencies below $1,000 \mathrm{~Hz}$ are given more weight when C-weighting is used (Kryter 1985). C-weighting is used in this assessment because this metric is the estimate of exposure that is generated by the blast noise model BNOISE2. It is generally thought to be a predictor of human annoyance and has been used for occasional wildlife studies (e.g., Telesco and van Manen 2006). With all of its uncertainties that will be discussed below, CSEL (C-weighted Sound Exposure Level) was determined to be the best available sound metric, that is, a single event noise measure for which some response information is available.

Hellfire missiles do not generate a sonic boom during launch and flight of the missile. Therefore, sound intensity measures peculiar to that type of sound are not required or considered in this assessment. 


\section{S. Jones et al.}

Distance. The distance from an explosion to an animal is an exposure metric in some exposure-response relationships for blast noise. Distance is an indicator of average expected sound exposure, but actual levels can vary significantly from the mean under various meteorological conditions.

\section{Temporal measures}

Temporal aspects of exposure include duration, frequency of occurrence, and timing. Duration is accounted for by the SEL metric. None of the available exposureresponse models use frequency of detonation (e.g., number of blast events per day or week) as a temporal measure of exposure, but frequency could be qualitatively used to estimate the likelihood of habituation of wildlife to missile firing. The timing of Hellfire testing is important as it relates to reproductive behavior and home range locations.

\section{Spatial measures}

Spatial measures of exposure include the spatial extent of the flight path; the spatial extent of craters made by missiles that miss their targets; the spatial extent of the debris field (i.e., shrapnel) or burn area; the habitats, home ranges, forage and water locations of mule deer; and the area where mule deer potentially receive substantial exposure to blast noise or shrapnel.

\section{Selection of Measures of Effects}

The primary measures of effects are observed behavioral responses of ungulates or surrogate mammals such as humans to blast noise, including hearing damage and behavioral effects. Where indirect effects to deer might have occurred via effects on vegetation, changes in quality or area of deer habitat would also be a measure of effect.

\section{GHARACTERIZATION OF EXPOSURE}

\section{Direct Exposure of Mule Deer to Stressors of Missile Detonation and Impact Sound contours calculated using BNOISE2}

Sound levels experienced by mule deer were not measured in this study. Therefore, sound levels on the ground were estimated using BNOISE2, a U.S. Army software program that calculates and displays blast noise exposure contours resulting from specified operations involving large guns and explosive charges.

\section{Program structure}

BNOISE2 is a relatively new version of a computerized tool that replaced the BNOISE computer program, which had been a primary model for blast noise assessment for more than 20 years. The model was in beta testing at the time of this study and is now undergoing validation (by coauthor L. Pater) for training operations at a military installation. BNOISE2 offers improved propagation algorithms, updated weapons source models, and an improved user interface (US Army 2003). The software runs under the Microsoft Windows ${ }^{\mathrm{TM}}$ operating systems and includes 
consideration of type of weapon and ammunition, number and time of rounds fired, range attributes, weather, and assessment procedures and metrics. It also accounts for spectrum and directivity of both muzzle blast (or launch) and projectile sonic boom, which facilitates accurate calculation of propagation and sound frequency weighting. Source model parameter values are based on empirical data. The propagation algorithms are based on sophisticated calculations and experimental data. Available metrics include CSEL, peak level, and day-night noise level (DNL) (US Army 2003).

Information regarding the types of weapon and ammunition, the locations at which the firing takes place, the number of shots during daytime and nighttime, and so on, is entered into an activity table in BNOISE2. Required information regarding the guns and ammunition (source models) and ranges is stored in databases and chosen from lists. A library of database records, including weapons, metrics and frequency weighting schemes, is included with the program.

The propagation algorithm is used to calculate sound levels at each node of a user-defined geographical grid. The resulting array of noise level values is converted to contours.

\section{Implementation for Apache-Hellfire test at YPG}

Five attack runs for Apache Longbow AH-64-Hellfire testing were simulated in the exposure assessment for helicopter overflights (Efroymson et al. 2008b, in press). For the purpose of this risk assessment, a single attack simulation was run in BNOISE2 for the following reasons: (1) The principal noise from firing a Hellfire missile is the explosion of the warhead at the target (i.e., launch noise is so insignificant that it is not included in the program). Thus, differences in launch points for the five test firings evaluated in the Apache Longbow-Hellfire missile test at YPG would not affect the exposure estimates for mule deer, as long as impact location was identical; (2) Definitive information on impact locations was not available; therefore, all targets were assumed to be at or near the Pinkrock Impact Point (IP, Figure 1 in Efroymson et al. 2008a, in press); (3) Multiple explosions did not occur simultaneously, thus eliminating the need to model overlapping contour levels.

All noise level distances were measured from the Pinkrock IP. The noise level contours for the Hellfire missile were expressed in terms of CSEL. Contours were plotted for the effects thresholds and selected intermediate exposure levels. Contours were exported as shapefiles to ArcView. The noise contour output map, draped on a Landsat 7 image, is presented as Figure 2.

The sound level at a given location for a given noise source is highly dependent on sound propagation conditions, which are strongly influenced by meteorological conditions such as wind and temperature variation in the atmosphere. The BNOISE2 default sound propagation conditions were used for the Hellfire simulation at YPG. These default conditions are represented by statistical distributions of possible conditions. Sound propagation accounts for the substantial variations shown in the table of statistical expectations for noise level at a given distance from the impact location (Table 2). Topographic features may also influence the received sound level at a given location. Although BNOISE2 is capable of accounting for topography, this data layer was not incorporated into the Hellfire simulations. This lack of topographic 


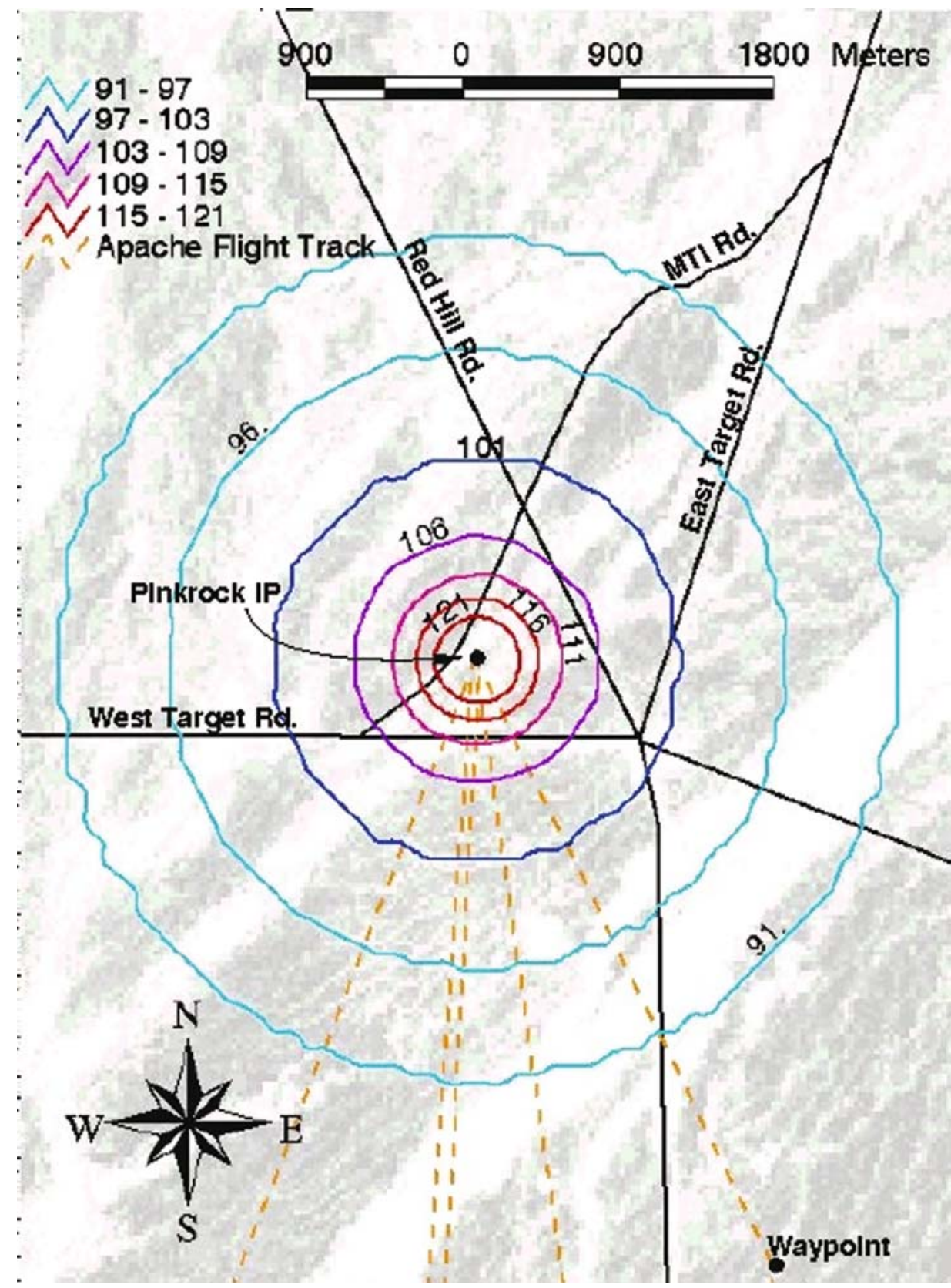

Figure 2. C-weighted decibel sound contours in Sound Exposure Level (SEL) metric, produced using BNOISE2 software, draped over Landsat 7 image of study site. The impact location is assumed to be located at Pinkrock Impact Point (IP), the northernmost point of the Apache flight track. The Apache flight track is equivalent to the Hellfire trajectory. Contour levels are for a single explosion of a Hellfire warhead. The depicted waypoint is one of several locations where the helicopter changed direction. 
Table 2. Hellfire warhead blast noise level statistics at 2432 meters distance, based on variability in weather conditions. ${ }^{1}$

\begin{tabular}{lcc}
\hline Exposure Level,CSEL $(\mathrm{dB})$ & Peak Level,PK $(\mathrm{dB})$ & Percent Exceeding Sound Level \\
\hline 116 & 141 & $0.13(\mu+3 \sigma)$ \\
109 & 134 & $2.28(\mu+2 \sigma)$ \\
100 & 125 & $15.87(\mu+1 \sigma)$ \\
91 & 115 & $50.00(\mu+0 \sigma)$ \\
82 & 106 & $84.13(\mu-1 \sigma)$ \\
76 & 100 & $97.72(\mu-2 \sigma)$ \\
\hline
\end{tabular}

${ }^{1}$ Statistics generated from BNOISE2 simulation of a Hellfire detonation under average weather conditions. Predicted variations in blast noise at 2432 meters is represented by the estimated percentage of blasts that would exceed various exposure levels. This variation is primarily due to assumed variations in weather conditions.

specificity was determined to be relatively insignificant and acceptable because of the location of the test between mountain ranges (rather than on a mountain).

Thus, over a wide range of sound propagation conditions that might be expected to occur, a mean CSEL of $91 \mathrm{~dB}$ is predicted at a distance of about 2.4 kilometers from the explosion, with a standard deviation of about $8 \mathrm{~dB}$. A mean CSEL of 116 $\mathrm{dB}(140 \mathrm{~dB}$ peak) is predicted to occur at a distance of about 350 meters from the detonation.

\section{Model uncertainty}

BNOISE2 is the best acoustic model currently available for predicting sound levels associated with weapons firing and detonation. However, these are complicated processes to simulate, and substantial uncertainties remain. For the past several years, efforts have been focused on improving the prediction sensitivity to changes in weapon size, vegetation, weather, and terrain (CERL 1998).

\section{Sound exposure based on distance}

As with the exposure assessment for the Apache Longbow helicopter (Efroymson et al. 2008b, in press), the distance from a sound source (e.g., an aircraft or a Hellfire detonation) to an animal is an alternative exposure metric to direct measurement of sound. That is, distance can be related to ecological effects if assumptions are made about locations of deer during detonation. Unlike exposures to aircraft, sight of the Hellfire missile by the animal is, for purposes of this demonstration of MERAF, assumed not to affect the distance at which a response is elicited. This assumption is based on the small size and the high velocity (i.e., short duration of visibility) of the missile. Therefore, distance from the blast is assumed to be primarily a measure of sound exposure.

The activity description, specifically the location of the detonation, assumed to be at Pinkrock IP, serves as the exposure assessment for the distance-response relationship. Locations of individual deer are not known, so is not possible to calculate the distance to each animal. 


\section{S. Jones et al.}

\section{Other blast-related stressors}

A radius for the shrapnel impact zone around the Hellfire impact point was not available for this assessment. In a more comprehensive assessment, site- and weaponspecific information could be used to generate a reasonable exposure estimate. For example, one could measure the density of shrapnel per unit area with distance from the point of detonation. This could be done under standardized conditions or after each detonation at the specific site to be evaluated. Direct impacts of ordnance on deer would be a much more credible pathway if the scale of the program were larger (e.g., a training program), the impact zone were less well defined, and the ecosystem were more heavily vegetated than the desert pavement of YPG.

Environmental concentrations of residual chemicals were not available for this assessment. In a more comprehensive assessment, this information could be obtained through site sampling, fate and transport modeling of known residues of Hellfire missiles, or a combination of the two.

\section{Population issues}

As stated in the companion manuscript, the assessment area for the local population is $126 \mathrm{~km}^{2}$ (Efroymson et al. 2008a, in press). When extrapolating from exposures for individuals to exposures for the population, the time scale of the test must be considered. The aforementioned exposure estimates are for a single Hellfire detonation, but the August 2000 test consisted of five Hellfire detonations at roughly the same impact point over eight days. A conservative approach to estimating the fraction of the local population that was exposed (at a specified threshold level) over the duration of the test period would be to assume that some individual deer were replaced by others during the test. However, data are not available to estimate the number of deer that might enter the various zones of exposure over the duration of the test period, especially because the Apache-Hellfire tests might disrupt this normal pattern of movement. It is assumed in this assessment that the high estimate of population density (Efroymson et al. 2008a, in press) provides sufficient conservatism to allow for the possibility that some deer entered the assessment area during the test period.

\section{Indirect Exposure of Mule Deer via Disturbance of Vegetation in Washes}

Mule deer populations could be adversely affected by missile detonations through effects on habitat consisting of desert wash vegetation (Figure 1). (Desert washes are areas with relatively dense or tall vegetation where water flows intermittently after heavy rains.) The characterization of exposure of vegetation in washes to Hellfire missiles is conceptually analogous to the assessment of exposure to tracked vehicles (Peterson et al. 2008, in press). Direct exposures of desert wash vegetation to Hellfire missiles would include: (1) misses that detonate in the wash and obliterate vegetation in the impact crater, (2) shrapnel from hits and misses that damage vegetation in the immediate area of the impact, (3) fires ignited by hits or misses that damage vegetation near the impact area, and (4) contaminants from shrapnel. We assume that direct exposures of vegetation did not occur during this Hellfire test because the target was never missed. In addition, the vehicular targets were located 
on the MTI Road or at the Pinkrock IP and not in washes. Furthermore, targets (tanks) avoid traveling through washes at YPG.

Indirect exposure of vegetation to Hellfire missiles would consist of changes in hydrology due to misses up-gradient of the wash area. Craters in the desert pavement have the same effect as tank tracks (i.e., ponding of water and potentially increased permeability, Peterson et al. 2008, in press), and exposure could be modeled in the same manner if the spatial resolution of the model were adequate for small craters. However, all Hellfire missiles hit their targets in the August 2000 test, eliminating the need to characterize indirect exposures to wash vegetation. (A miss had occurred in previous tests.) The likelihood of misses might be expected to increase during training missions, because of the increased number of sorties and because trainees may be less familiar with particular weapons and aircraft than military personnel who regularly test them. In contrast, developmental weapons may have a higher rate of failure than weapons in general use (Efroymson et al. 2008, in press). Because exposures of vegetation to missile-related stressors were not present in this test, the indirect pathway of stress from vegetation to mule deer is not considered further.

\section{CHARACTERIZATION OF EFFECTS}

\section{Mule Deer}

\section{Assessment endpoint property}

The selected assessment endpoint property is the abundance or production of desert mule deer. As with the effects assessment for the Apache Longbow (Efroymson et al. 2008b, in press), one would need to extrapolate qualitatively from behavioral effects in individuals to population-level effects. In Efroymson and Suter. (2001), we discuss how an assessor might get from a behavioral measure of effect to a reproductive assessment endpoint and depict example mechanisms. For example, startle reactions could interrupt foraging, leading to a change in abundance or production. However, not even behavioral effects of blast noise are known for ungulates, thus requiring further extrapolation from less related species (i.e., humans) for which qualitative and vague "disturbance" effects information is available.

\section{Sound level effects thresholds}

To assess noise impact for any species, one must first have dose-response information. This requirement is problematic, because the response to noise varies from species to species for a given type of noise, and also with type of noise for a given species. The most studied species in this regard is human beings. The human response criteria (ANSI 1996) for large arms, small arms, and aircraft noise are all different. No data are available for response of mule deer or other ungulates to low frequency blast noise. Therefore, we extrapolated from human response data to illustrate how more exact and relevant information would be used.

Blast noise exposure is expressed in terms of CSEL. Human response is usually judged in terms of annoyance or likelihood of complaints. It is the experience of one 


\section{S. Jones et al.}

of the authors ${ }^{1}$ that, for large explosions such as missile warheads, humans would almost never complain if the CSEL is lower than about $91 \mathrm{~dB}$ (about $115 \mathrm{~dB}$ peak sound level). Complaints from a very small percentage of humans become somewhat likely ${ }^{2}$ if the CSEL exceeds about $106 \mathrm{~dB}$ (about $130 \mathrm{~dB}$ peak sound level). A very conservative threshold for hearing damage to humans is a $140 \mathrm{~dB}$ peak sound level (Mil. Std. 1474D, Department of Defense Design Criteria Standard: Noise Limits, February 12, 1997), which is equivalent to a CSEL of about $116 \mathrm{~dB}$. No data are available for judging whether this threshold is predictive of behavioral responses of other mammals such as mule deer.

In the absence of more pertinent information, we selected the exposure levels of 91 and $116 \mathrm{~dB}$ CSEL, which correspond to estimated thresholds for disturbance and hearing damage in humans, respectively. (Our purpose is the demonstration of a risk assessment framework; we do not recommend these quantities as effects levels for general use in ecological risk assessments.) It is assumed in this assessment that disturbance is equivalent to behavioral impacts. As noted previously, no data are available to support these thresholds for ungulates, nor indeed are there rigorous data for humans. Experience suggests that these criteria are in fact extremely conservative for humans, though data would be required to better define the actual degree of conservatism.

\section{Distance effects thresholds}

Distance thresholds are an alternative exposure-response model for effects of blast noise. Two types of potentially useful distance thresholds can be estimated: (1) the greatest distance from the blast at which the selected response is observed, which is conceptually analogous to the Lowest-Observed-Adverse-Effects Level (LOAEL) for chemical effects assessment; and (2) the shortest distance from the blast at which the selected response is not observed, which is conceptually analogous to the NoObserved-Adverse-Effects Level (NOAEL) for chemical effects assessment.

Only one relevant study reporting distance thresholds was found (Andersen et al. 1996). It consisted of a comparison of general types of military disturbances for their ability to elicit short-term behavioral and physiological responses in moose (Alces alces). Cannonfire was the only disturbance tested for which blast noise would be the stressor. Moose did not respond to the blast noise, so the only distance threshold reported for cannonfire was a minimum distance from the blast at which no response was observed (i.e., the NOAEL), $400 \mathrm{~m}$. Assuming the exposure area can be defined by a symmetrical circle with a radius of $400 \mathrm{~m}$, the zone of disturbance would consist of $0.50 \mathrm{~km}^{2}$. The usefulness of this threshold is uncertain, because the characteristics of the cannon (e.g., type, size, or munitions used) and the blast noise (e.g., direction of muzzle relative to receptor location or CSEL at a nominal distance, such as 1 meter) were not provided. Thus, it is unclear how blast noise from a Hellfire missile would compare to that of cannonfire in Andersen et al. (1996).

\footnotetext{
${ }^{1}$ Larry Pater of the U.S. Army Corps of Engineers Construction Engineering Research Laboratory has approximately 20 years of experience in acoustics engineering and bioacoustics and provided these data.

${ }^{2}$ No reliable statistical data are available.
} 
It is interesting to note that Andersen et al. (1996) also evaluated the responses of moose to helicopters on six different occasions. They observed a maximum distance at which moose would flush from cover ( $i$. e., a LOAEL) of $50 \mathrm{~m}$ and a minimum distance of approach of the helicopter at which no response was observed (i. e., the NOAEL) of $400 \mathrm{~m}$. That is, the NOAEL distance for cannonfire was the same as for the helicopter, and both were an order of magnitude greater than the LOAEL distance for the helicopter.

\section{Other blast-related stressors}

Blast noise is not the only potential stressor for mule deer. Shrapnel and possibly fire could also injure mule deer in the immediate area of the impact point or affect their behavior in the vicinity. The obvious measure of these effects is the number of injured deer. For example, Dinkines et al. (1992) attributed 39\% of the mortality of white-tailed deer at Fort Sill, OK, USA, to artillery munitions, based on carcasses found within $20 \mathrm{~m}$ of an ordnance crater. Deer morbidity could be estimated based on a distance or area within which injury to mule deer has a specified likelihood. For example, an effective impact zone radius might be based on the average size of a mule deer and the distance from the detonation at which the density of shrapnel (i. e., shrapnel per unit area) suggests that an organism that size would have a $20 \%$ likelihood of being hit by shrapnel. No data are available to support this approach in this assessment. In a more realistic assessment, site- and weapon-specific information could be used to generate this type of estimate.

A survey of the impact area for mule deer could be performed during and after the tests to determine whether or not deer were injured by shrapnel from the tests. Such effects were not reported for the August 2000 Hellfire tests at YPG, but an extensive search for injured animals was not performed. Contamination of the environment with residual chemicals could also be evaluated in a comprehensive assessment, provided that toxicological data are available for most or all of known constituents of Hellfire warheads. This information could come from lab and field studies of individual chemicals or relevant combinations of chemicals.

\section{Necessary extrapolations}

As in the Apache Longbow helicopter assessment, a major extrapolation (and major source of uncertainty) is the extrapolation from behavior of individuals to population-level effects. The mechanisms by which these extrapolations can occur for blast noise are essentially the same as for the Apache Longbow in Efroymson et al. (2008b, in press).

\section{Factors that modify magnitude of effects}

Habituation. Animals have in general been found to be much more tolerant of stimuli after they have learned by experience that a stimulus poses no threat to them. This is analogous to the habituation to low-altitude overflights that occurs for ungulates and other animals (Efroymson et al. 2008b, in press). As with the Apache Longbow, mule deer at Yuma Proving Ground might habituate to the Hellfire blast noise during the 3-week test period. Also, other weapons firing programs from aircraft platforms are ongoing in the general area. The first day of the test probably 


\section{S. Jones et al.}

determines if deer are going to move sufficient distances to change their home ranges. No data were found relating other potential modifying factors to mule deer responses to blast noise (e.g., animal activities, time of year, or type of vegetation cover).

\section{RISK CHARACTERIZATION}

\section{Expected Behavioral Impacts on Mule Deer, Based on CSELs}

The selected threshold for behavioral impacts is $91 \mathrm{~dB}$ CSEL, although it is acknowledged that human annoyance is also factored into this threshold. The area within which Hellfire detonations are expected to produce sound levels greater than or equal to that threshold was estimated with BNOISE2 at $18.1 \mathrm{~km}^{2}$. This area is approximated by a circle with a radius of $2.4 \mathrm{~km}$ centered at the Pinkrock IP. For the purposes of methods demonstration, mule deer within this zone of disturbance were assumed to be subject to behavioral impacts. Mule deer densities for the approximately $126 \mathrm{~km}^{2}$ YPG Apache-Hellfire test area have been conservatively $(i$. $e$., over-) estimated at 0.56 deer per $\mathrm{km}^{2}$, for an estimated local population of 70 mule deer (Efroymson et al. 2008a, in press). Based on these estimates, 10 deer (i. e., $18.1 \mathrm{~km}^{2} \times 0.56$ deer per $\mathrm{km}^{2}$ ) would be expected to exhibit a behavioral response (disturbance) per Hellfire test detonation. That would constitute $14.3 \%$ of the local population. As stated earlier, these are assumed to be the same deer during every detonation.

\section{Expected Behavioral Impacts, Based on Distance}

The only relevant behavioral distance threshold for blast noise is the minimum distance at which moose did not respond to cannonfire, $400 \mathrm{~m}$ (Andersen et al. 1996). This distance is conceptually analogous to the NOAEL for chemical effects assessment. The area within which Hellfire detonations are expected to meet or exceed that threshold was estimated at $0.50 \mathrm{~km}^{2}$. This area is approximated by a circle with a radius of $400 \mathrm{~m}$ centered at the Pinkrock IP. Mule deer within this zone of disturbance may be conservatively assumed to exhibit a behavioral response. Based on the estimated mule deer densities for the YPG Apache-Hellfire test area, not even a single deer (i.e., $0.5 \mathrm{~km}^{2} \times 0.56$ deer per $\mathrm{km}^{2}=0.28$ deer; $0.4 \%$ of the local population) would be expected to exhibit a behavioral response per blast or per 5-Hellfire-blast test series. (If deer were assumed to be different individuals for each test blast, still only one deer would be expected to be affected per 5-Hellfire-blast test series.)

This estimate is likely to be conservative with respect to moose, because it assumes that adverse effects occur just inside that 400-m radius, but mule deer may be more skittish. An approach for estimating chemical LOAELs when only NOAELs are available is to apply a NOAEL:LOAEL conversion factor to the NOAEL. Dividing the distance NOAEL by 10 , which is a commonly used extrapolation factor, ${ }^{3}$ yields an estimated maximum distance of $40 \mathrm{~m}$ from the stressor at which moose would be

\footnotetext{
${ }^{3}$ Safety factors and other extrapolation factors are typically agreed to by regulatory agencies and other risk managers. Thus, the specific conversion factor of 10 is chosen for illustration only.
} 
expected to flush. That is approximately the distance at which the combined sight and sound of helicopters caused moose to flush (Andersen et al. 1996). That distance would correspond to an area of $5000 \mathrm{~m}^{2}\left(0.005 \mathrm{~km}^{2}\right)$ and to far less than one (0.003) of the estimated 70 mule deer comprising the local population. Even using a more conservative conversion factor of three corresponds to less than one $(0.008)$ mule deer (i.e., a maximum distance of $133 \mathrm{~m}$ yields an area of $14,000 \mathrm{~m}^{2}$ ). However, density estimates would vary with sources of water, minerals, and food.

\section{Expected Hearing Damage, Based on CSEL}

The selected threshold for hearing damage, based on human data, is $116 \mathrm{~dB}$ CSEL. The area within which Hellfire detonations are expected to produce sound levels greater than or equal to that threshold was estimated with BNOISE2 at 0.385 $\mathrm{km}^{2}$. This area is approximated by a circle with a radius of $350 \mathrm{~m}$ centered at the Pinkrock IP. Mule deer within this zone of injury are assumed to experience temporary or permanent hearing loss. Based on the estimated mule deer densities for the approximately $126 \mathrm{~km}^{2}$ YPG Apache-Hellfire test area, no single deer (i.e., $0.385 \times$ $0.56=0.22$ deer; $0.3 \%$ of the local population) would be expected to be injured per Hellfire test detonation or per 5-missile test series. This estimate is only slightly lower than the estimate of deer behaviorally disturbed based on the slant distance metric.

\section{Expected Effects from Other Blast-Related Stressors}

Shrapnel and possibly fire could also injure mule deer in the immediate area of the impact point or affect their behavior in the vicinity of the impact point. If exposureresponse data relating the distance from the impact point at which shrapnel would be expected (with a specified probability) to injure an animal (with a specified level of severity) were available, then the risk estimation methods used above for blast noise could be used here also. That is, one could estimate the number of deer expected to be in the zone of physical injury and relate that to the number of deer in the local population. However, (1) it is highly unlikely that mule deer would stay in the immediate vicinity of moving tank targets, and (2) the zone of shrapnel and fire disturbance would not be likely to encompass even one deer, given the density of 0.56 deer $/ \mathrm{km}^{2}$ (1 deer per $1.8 \mathrm{~km}^{2}$ ).

\section{Population Issues}

The primary issue in estimating effects on the local mule deer population from Hellfire testing is the need to extrapolate from hearing damage and disruption of behavior of individuals to population-level effects (e.g., reproduction). As in the Apache Longbow helicopter assessment (Efroymson et al. 2008b, in press), no known data are available that would allow an assessor to perform those extrapolations quantitatively. Indeed, reliable data are not even available for blast noise effects on individual mule deer. Given that a principal purpose of this assessment is to demonstrate the general MERAF process, and given that few response data are available for the missile firing activity, it is assumed herein that the hypothetical effects on individuals constitute a highly conservative estimate of impacts on the population. That is, if the percentage of behavioral effects in the mule deer population does not exceed 


\section{S. Jones et al.}

an acceptable level of effect for the assessment endpoint (e.g., 20\% decrement in abundance or reproduction), then we could be confident that population-level effects also would not exceed the acceptable level of effect.

\section{Weight of Evidence}

Criteria for weighing evidence are described in the companion article, Efroymson et al. (2008b, in press). Although the exposure and effects levels used in this assessment are not based on reliable, quantitative data for mule deer, they are considered herein using the weight of evidence process for demonstration purposes (Table 3).

\section{Behavioral effects}

The weight of evidence suggests that the Hellfire component of the Apache Longbow test program would not elicit a behavioral response from a substantial portion $(\geq 20 \%)$ of the local population and would, therefore, not substantially affect abundance or reproduction of the local mule deer population. The risk estimate derived using the BNOISE2-predicted zone of disturbance indicated that 10 deer would be expected to exhibit a behavioral response per Hellfire test detonation. However, the risk estimate derived using the minimum distance at which moose flush in response to cannonfire indicated that fewer than one deer would be expected to exhibit a behavioral response per Hellfire test detonation (which is also equivalent to fewer than one deer per the Hellfire component of the Apache-Hellfire test program). Neither highly uncertain line of evidence is clearly superior to the other.

The exposure estimates produced by BNOISE2 are better than those reported in the study of moose responses to military disturbances (Anderson et al. 1996). BNOISE2 is a fairly sophisticated sound propagation model that accounts for the relevant characteristics of the missile and environmental variables (climate, topography), and its results are given in a metric that has relevance to wildlife (i.e., CSEL). In contrast, none of the characteristics of the cannonfire were reported by Anderson et al. (1996), which precludes relating exposure to that cannonfire to exposures to Hellfire missile detonations. The effects data, on the other hand, are somewhat better for the cannonfire tests than for the BNOISE2 simulations. The CSEL threshold for disturbance is based on the authors' experience that humans almost never complain about large explosions if the CSEL is below $91 \mathrm{~dB}$. Although experience suggests that these criteria are very conservative for humans, no data are available to support these or any other behavioral, hearing, or reproductive thresholds for ungulates. In contrast, the distance threshold for disturbance is based on tests of blast noise with an ungulate, the moose (A. Alsec). The measured responses, flushing from cover and increased heart rate, are good measures of effects and relate well to those used for mule deer. This measure of effects is also conservative, given that it is based on the lack of an effect at the specified distance.

The weight of evidence suggests that the Hellfire component of the Apache Longbow test program does not disturb a substantial fraction of the local population and would, therefore, not substantially affect abundance or reproduction of the local mule deer population. Both the sound level- and distance-based risk estimates indicate that, at most, only a small fraction of the local population would be affected. The risk estimate derived using the BNOISE2-predicted zone of disturbance indicated 


\section{Apache Longbow-Hellfire Missile Test: Ecological Risk Assessment}

that $14 \%$ of the local population would be expected to exhibit a behavioral response per Hellfire test detonation. The assumption that exposed deer in each of the five test firings are largely the same deer may underestimate the fraction of the population that is disturbed at least once during the entire test period. However, animals exposed multiple times to a blast are likely to become habituated and not to exhibit the disturbance response.

Table 3. Summary of the risk characterization ${ }^{1}$ for the desert mule deer population exposed to Hellfire missiles in the $126-\mathrm{km}^{2}$ assessment area in Cibola Range, Yuma Proving Ground.

\begin{tabular}{|c|c|c|c|}
\hline Evidence & $\begin{array}{c}\text { Behavioral } \\
\text { Effect } \\
\text { Result }^{2}\end{array}$ & $\begin{array}{l}\text { opulation- } \\
\text { level } \\
\text { Effect }^{3} \\
\text { Result }\end{array}$ & Explanation \\
\hline $\begin{array}{l}\text { CSEL/ungulate } \\
\text { behavior relationship }\end{array}$ & - & - & $\begin{array}{l}\text { The risk estimate derived } \\
\text { using the } \\
\text { BNOISE2-predicted zone } \\
\text { of disturbance indicated } \\
\text { that } 10 \text { deer in the } 126 \mathrm{~km}^{2} \\
\text { area would be expected to } \\
\text { exhibit a behavioral } \\
\text { response per Hellfire test } \\
\text { detonation. That } \\
\text { corresponds to } 14 \% \text { of the } \\
\text { local population. }\end{array}$ \\
\hline $\begin{array}{l}\text { Distance/ ungulate } \\
\text { behavior relationship }\end{array}$ & - & - & $\begin{array}{l}\text { The distance-based risk } \\
\text { estimate indicated that } \\
\text { zero deer in the } 126 \mathrm{~km}^{2} \\
\text { area would be expected to } \\
\text { exhibit a behavioral } \\
\text { response to a Hellfire test } \\
\text { detonation. Thus, } \\
\text { population-level effects are } \\
\text { not expected, based on this } \\
\text { line of evidence. }\end{array}$ \\
\hline $\begin{array}{l}\text { CSEL/hearing damage } \\
\text { relationship }\end{array}$ & - & - & $\begin{array}{l}\text { The risk estimate derived } \\
\text { using the } \\
\text { BNOISE2-predicted zone } \\
\text { of injury indicated that } \\
\text { zero deer in the } 126 \mathrm{~km}^{2} \\
\text { area would be expected to } \\
\text { exhibit a behavioral } \\
\text { response per Hellfire test } \\
\text { detonation. Thus, } \\
\text { population-level effects also } \\
\text { are not expected, based on } \\
\text { this evidence. } \\
\text { (Continued on next page) }\end{array}$ \\
\hline
\end{tabular}




\section{S. Jones et al.}

Table 3. Summary of the risk characterization ${ }^{1}$ for the desert mule deer population exposed to Hellfire missiles in the $126-\mathrm{km}^{2}$ assessment area in Cibola Range, Yuma Proving Ground. (Continued)

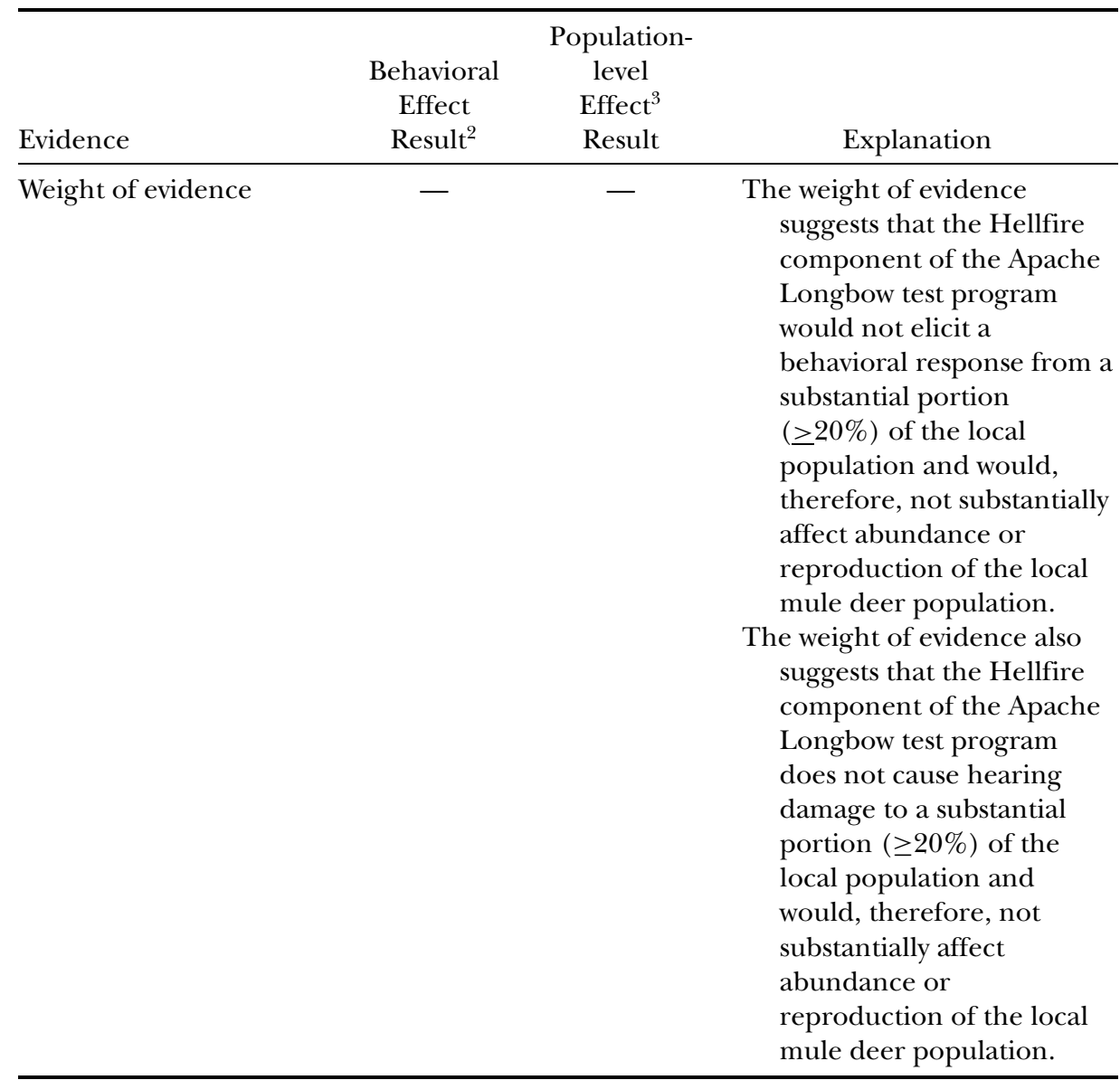

\footnotetext{
${ }^{1}$ The authors have low confidence in the risk characterization for the Hellfire missile activity because of the paucity of relevant effects data.

${ }^{2} \mathrm{An}$ effect is presumed to be negative if fewer than $20 \%$ of the mule deer are affected.

${ }^{3}$ Level of confidence in population-level effect would be low even if a large-scale behavioral effect was predicted.
}

Because the lines of evidence did not indicate a significant risk for individuals, it follows that there would not be a risk to the population.

\section{Hearing damage}

The weight of evidence suggests that the Hellfire component of the Apache Longbow test program does not cause hearing damage to either individuals or the local population and would, therefore, not substantially affect abundance or reproduction 


\section{Apache Longbow-Hellfire Missile Test: Ecological Risk Assessment}

of the local mule deer population. Only one line of evidence, the sound level-based risk estimate, was available. That hypothetical estimate indicated that not even one deer would be exposed to potentially damaging sound levels. Regarding the effects level, the CSEL threshold for injury is based on a very conservative threshold for hearing damage for humans, although no data are available for judging whether this threshold is valid for mule deer.

\section{Combined modes of action}

The weight of evidence suggests that the five blasts of the Hellfire component of the Apache Longbow test program would disturb few deer, would not cause hearing damage to a single deer, and would not cause injury to any deer due to shrapnel or fire.

\section{New information}

At least two relevant investigations have been published since this ecological risk assessment was undertaken. In the first, black bears at Camp Lejeune did not respond to weapons firing through local movements (Telesco and van Manen 2006). An exception is that younger bears moved away from high disturbance noise zones (>70 dB CSEL) more than older bears. However, at larger scales (daily movement scales and annual home range scales), bears avoided high disturbance noise zones. The authors attribute the avoidance partly to lack of forest structure and camping of military personnel near firing positions, as well as to noise. This study of a military training program is only partly relevant to our study of a military testing program, because in the former, firing exercises occurred on 149 of 317 monitoring days (Telesco and van Manen 2006), that is, much more frequently than the firing in the YPG test. Nonetheless, any study of wildlife population impacts of noise from military programs would benefit from radiotelemetry conducted at large spatial and temporal scales.

In a second study, Sonoran pronghorn exposed to bombing, strafing, smoke, and/or heat flares at Barry M. Goldwater Range did not display abnormal behavioral changes, nor did any animals move $\geq 10 \mathrm{~m}$ when any of these military activities were present (Krausman et al. 2004). Across 3 years, 592 such events were monitored, a much higher frequency of event than the missile firings in this study. Although sound levels and distances of pronghorn from detonation points were not measured, this study confirms somewhat the negative results of our study.

\section{Uncertainty and Variability}

Sources of uncertainty and variability that are likely to affect this assessment have been discussed throughout the preceding sections. Major issues with respect to the risk assessment for the Hellfire component of the Apache Longbow test are:

- No quantitative exposure-response data for blast noise and ungulates are available. The CSELs used herein are for "disturbance" and acoustic thresholds of humans, and the exposure characteristics for the cannonfire tested with moose were not specified. 


\section{S. Jones et al.}

- No quantitative data relating behavioral responses of individuals to populationlevel effects (i.e., abundance and reproduction) are available.

- Terrain was not included in the BNOISE2 simulations, although the capability is available.

- The extent of validation of the BNOISE2 model is unknown.

- Exposure and/or effects data are not available for other Hellfire-related stressors (i.e., shrapnel and fire) and ungulates.

- The number of mule deer in the assessment area at the time of the Hellfire missile test is uncertain.

\section{RESEARCH GAPS}

Additional data and methods that are needed to improve the assessment of risks from missile testing and training flow from the uncertainties identified throughout this article. The primary data gap for missile tests is the lack of quantitative exposureresponse data for blast noise and common wildlife receptors. Efforts to fill this gap should focus on receptors that are likely to be sensitive and exposed at missile testing and training facilities (e.g., mule deer, antelope, and other ungulates). Potentially useful studies could include tests with individual animals where exposure (e.g., CSEL at receptor and distance from blast), effects (e.g., distance flushed and heart rate), and habituation could be measured under controlled conditions (e.g., fixed test charges) or field tests with representative munitions (e.g., Hellfire missiles) and free ranging animals.

Research on the relative sound frequencies that vertebrates other than humans hear is needed. C-weighted decibels do not necessarily reflect ungulate or mule deer hearing. Similarly, thresholds for hearing damage could be investigated.

Another major source of uncertainty is the lack of data relating behavioral responses of individuals to population-level effects ( $i$. e., abundance and reproduction). Studies relating measurable responses for individuals (e.g., distance flushed, number of times flushed, and degree of habituation) to relevant measures of population-level effects (e.g., calving success or population abundance) would be the most useful from a risk assessment perspective. An ideal study of desert mule deer that would support this risk assessment or a larger scale assessment for a training program would be conducted with Hellfire missiles and free-ranging desert mule deer. Such a study would examine behavioral effects on all age and sex classes, especially during sensitive times for reproduction, as well as more direct measures of reproduction (e.g., fawning success).

For Hellfire missiles, exposure and effects data could be helpful for common ecological receptors and stressors other than sound (e.g., shrapnel and fire). These data might include the density of shrapnel per unit area with distance from the point of detonation, the likelihood and spatial extent of fires, and the severity of injury caused by shrapnel and fire. The research would be more pertinent to larger scale testing or training programs than small tests, because tests at a small scale could not cause adverse effects to a population. In addition, for a retrospective risk assessment, it would be possible to survey the area for impacts on plants and vertebrates. However, the shrapnel model described earlier could be useful for prospective assessments. 


\section{ACKNOWLEDGMENTS}

This research was funded by a contract from the U.S. Department of Defense Strategic Environmental Research and Development Program (SERDP) project CS1054, A Risk Assessment Framework for Natural Resources on Military Training and Testing Lands, to Oak Ridge National Laboratory (ORNL), which is managed by UT-Battelle, LLC, for the U.S. Department of Energy under contract DE-AC05-00OR22725. We thank Bob Holst and John Hall for serving as project sponsors and Winifred Hodge Rose and Keturah Reinbold of the U.S. Army Corps of Engineers Construction Engineering Research Laboratory (CERL) for serving as Co-Principal Investigators. We also acknowledge the contributors of data, guidance, manuals, programming advice, text reviews, activity descriptions, and other assistance: Valerie Morrill, Chuck Botdorf, and Junior Kerns from YPG Environmental Sciences Division; Sergio Obregon, David McIntyre, and Bruce Goff from Jason \& Associates,YPG Office; Rick Douglas and Bert Evans from YPG Aviation and Airdrop Systems; Dick Gebhart and Kim Majerus from CERL; Todd Kuiken, Paul Hanson, and Robert Washington-Allen from ORNL; and Catherine Stewart from the U.S. Army Center for Health Promotion and Preventive Medicine.

\section{REFERENGES}

Andersen RJ, Linnell DC, and Langvatn R. 1996. Short term behavioural and physiological response of moose Alces alces to military disturbance in Norway. Biol Conserv 77:169-76

ANSI (American National Standards Institute, Inc.). 1996. Quantities and Procedures for Description and Measurement of Environmental Sound-Part 4: Noise Assessment and Long-Term Community Response. National Standard S12.9-1996, Part 4, Washington DC, USA

CERL (US Army Construction Engineering Research Laboratory). 1998. CERL'S Blast Noise Propagation Research Program. Champaign, IL, USA. Available at http://owww.cecer. army.mil/facts/sheets/LL10.html

Delaney DK, Pater LL, Melton H, et al. 2002. Assessment of Training Noise Impacts on the Red-cockaded Woodpecker. Final Report. US Army Corps of Engineers, Engineer Research and Development Center, Construction Engineering Research Laboratory, Champaign, IL, USA

Dinkines WC, Lochmiller RL, Bartush WS, et al. 1992. Cause-specific mortality of white-tailed deer as influenced by military training activities in southwestern Oklahoma. J Wildl Diseases 28:391-9

Doresky J, Morgan K, Ragsdale L, et al. 2001. Effects of military activity on reproductive success of red-cockaded woodpeckers.J Field Ornithol 72:305-11

Efroymson RA and Suter GW II. 2001. Ecological risk assessment framework for low-altitude aircraft overflights: II. Estimating effects on wildlife. Risk Anal 21:263-74

Efroymson RA, Peterson MJ, Jones DS, et al. 2008a. The Apache Longbow-Hellfire missile test at Yuma Proving Ground: Introduction and problem formulation for a multiple stressor risk assessment. Hum Ecol Risk Assess (this issue)

Efroymson RA, Hargrove WW, and Suter GW II. 2008b. The Apache Longbow-Hellfire missile test at Yuma Proving Ground: Ecological risk assessment for helicopter overflight. Hum Ecol Risk Assess (this issue)

Efroymson RA, Morrill V, Dale VH, et al. Habitat disturbance at explosives-contaminated ranges. In: Sunahara G, Hawari J, Lotufo G, et al. (eds), Ecotoxicology of Explosives and Unexploded Ordnance, CRC Press, Boca Raton, FL, USA (in press) 


\section{S. Jones et al.}

Krausman PR, Harris LK, Blasch CL, et al. 2004. Effects of military operations on behavior and hearing of endangered Sonoran pronghorn. Wildl Monographs 157:1-41

Kryter KD. 1985. The Effects of Noise on Man, 2nd ed. Academic Press, Orlando, FL, USA

Lehman RN, Steenhof K, Kochert MN, et al. 1999. Effects of military training activities on shrub-steppe raptors in Southwestern Idaho, USA. Environ Manage 23:409-17

Merrill SB and Erickson CR. 2003. A G.P.S.-based method to examine wolf response to loud noise. Wildl Soc Bull 31:769-73

Peterson MJ, Hargrove WW, Efroymson RA, et al. 2008. The Apache Longbow-Hellfire missile test at Yuma Proving Ground: Ecological risk assessment for tracked vehicle movement. Hum Ecol Risk Assess (this issue)

Schueck LS, Marzluff JM, and Steenhof K. 2001. Influence of military activities on raptor abundance and behavior. Condor 103:606-15

Suter GW II, Reinbold KA, Rose WH, et al. 2002. Military Ecological Risk Assessment Framework (MERAF) for Assessment of Risks of Military Training and Testing to Natural Resources. ORNL/TM-2002/295. Oak Ridge National Laboratory, Oak Ridge, TN, USA

Telesco DJ and Van Manen FT. 2006. Do black bears respond to military weapons training? J Wildl Manage 70:222-30

US Army. 2003. Blast Noise Impact Assessment (BNOISE2) Computer Model, Version 1.3. 2003-07-03. US Army Construction Engineering Research Laboratories, Champaign, IL, USA

USEPA. 1998. Guidelines for ecological risk assessment. EPA/630/R-95/002F. Risk Assessment Forum, US Environmental Protection Agency, Washington DC 
Copyright of Human \& Ecological Risk Assessment is the property of Taylor \& Francis Ltd and its content may not be copied or emailed to multiple sites or posted to a listserv without the copyright holder's express written permission. However, users may print, download, or email articles for individual use. 